\title{
A Cradle-to-Grave Carbon Index (Cl) for Design, Construction and Operations of Site-Specific Buildings
}

\author{
Boggarm Setty ${ }^{1 *}$, and James Woods ${ }^{2}$ \\ ${ }^{1}$ CEO and Founder of Setty and Associates, Ltd., 3040 Williams Drive, Suite 600, Fairfax, VA 22031, USA \\ ${ }^{2}$ Indoor Environments Consultant, Waynesboro, VA 22980, USA
}

\begin{abstract}
During the 1970s, the Energy Utilization Index (EUI) was introduced in terms of the annual rate of energy used per unit of floor area in site-specific buildings. It indicates energy but not total resource use effectiveness of design alternatives compared to baseline values (i.e., targets). Because of increasing concerns about indoor and outdoor emissions from carbon-based products and processes, an analogous "Carbon Index" $(\mathrm{Cl})$ is here introduced as a cradle-tograve design tool for evaluating the performance of design alternatives in terms of carbon emitted throughout the five stages of a building's lifespan: siting, design, construction, operations, and demolition/recycling. This $\mathrm{Cl}$ is expressed as equivalent mass of $\mathrm{CO}_{2}$ per unit floor area $\left(\mathrm{CO}_{2} \mathrm{e}\right)$. At each stage, this $\mathrm{Cl}$ is determined as the sum-of-products of two factors: 1) "Primary Factors" (PF), scalars that are defined and quantified by the designer; and 2) "Carbon Impact Factors" (CIF), which are standardized $2 \times 1$ matrices that characterize the PFs in terms of "embodied" $\mathrm{CO}_{2} \mathrm{e}$ emissions in the materials, assemblies, and equipment that are installed in the building, and as $\mathrm{CO}_{2} \mathrm{e}$ emissions that are released during the "operations" of the building. This design tool is posited to foster more accurate calculations of carbon emissions for design alternatives.
\end{abstract}

\section{Introduction}

\subsection{Need for "Cradle-to-Grave" Carbon Indexing}

Previous attempts have been made by RICS, ASHRAE, and others to promulgate valid procedures that can be implemented so that indices for energy use and carbon emissions from a building, located on a specific site (i.e., site-specific), can be credibly forecast for the processes of siting, design alternatives, construction, operations, and demolition or recycling [1-6]. The desire for such indices has been driven, in part, by the evolution of design standards since the energy crises of the 1970s for evaluating energy use and high performance in buildings, such as the ASHRAE Standard 90 series since 1975 [2], and the 189 series since 2010 [3]. Through professional observations and computer-assisted searches, similar attempts have been identified [e.g.. 410]. As buildings have been designed and constructed to these higher performance standards, components and systems have become more energy efficient, and the calculated and actual outcome values in terms of indices, such as the Annual Building Energy Utilization Index or Intensity (e.g. EUI - kWh/GSM/year or Btu/GSF/year), have tended to decrease [4].

Accordingly, estimates of carbon emissions (see Glossary for italicized terms) from these buildings have also tended to decrease (e.g., net-zero-energy buildings NZEBs). This decrease is shifting the focus from reductions in carbon emissions associated with energy used during the operations of buildings (i.e., operational carbon) to energy and chemical processes used during other stages, before and after the operations phase of a project's lifespan (i.e., embodied carbon), such as carbon emissions during the manufacture of the materials, their transportation to the building site, the construction activities themselves, and the eventual demolition and disposal or recycling $[1,5,6]$.

The purpose of this article is to examine a unique perspective for sustainability; an iterative design process is likely to result in significantly different estimates of cradle-to-grave carbon indices compared with noniterative, post-design calculations.

\subsection{Concept of the Cradle-to-Grave Carbon Index}

The Carbon Index (CI lifespan$_{\text {, }}$, as introduced here, is a design tool to assist in the management of a contiguous balance between primary outcomes of occupant health, safety and well-being, and secondary outcomes of sustainability, including the use of energy, other natural resources, and economic capital throughout the lifespan of a building that is located on a specific site. This CI Ilifespan is expressed in terms of equivalent carbon (i.e., $\mathrm{CO}_{2} \mathrm{e}$ ) emitted through the five stages of a building's lifespan, as shown in Table 1 and Fig. 1. CIlifespan has two independent components: embodied and

\footnotetext{
* Corresponding author: bogisetty@setty.com
} 
operational. Thus, CIlifespan is a $2 \times 1$ matrix, as shown in Eq. (1) below.

$$
\mathbf{C I}_{\text {lifespan }}=\begin{gathered}
C I_{\text {lifespan }}[\text { embodied }] \\
C I_{\text {lifespan }}[\text { operational }]
\end{gathered}
$$

The individual components of $\mathbf{C} \mathbf{I}_{\text {lifespan }}$ will be referred to henceforth as $C I_{\text {lifespan [embodied] and }}$ $C I_{\text {lifespan [operational]. The sum of these two components }}$ will be represented as $C I_{\text {lifespan,em+op }}$.

Table 1. Overview of the five cradle-to grave stages in a building's lifespan

1. Selection and preparation of the site for a new building;

2. Design procedures that include: 1 ) reduction of carbon emissions as an additional design objective; and 2) the resultant selections and specifications for materials, equipment, and systems;

3. Construction processes that include acquisition and utilization of materials, energy and manpower;

4. Operation of passive and active building systems that include: fenestrations (e.g., windows and doors), HVAC, electrical, and plumbing and water treatment systems, over an assumed lifespan of the building (e.g., 30 years) $[1,7]$; and

5. End-of life treatments that include: reuse, recycling, or final disposal of the building and its materials.

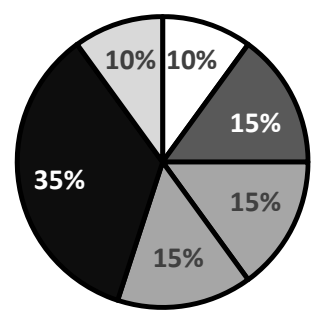

$$
\begin{array}{ll}
\boldsymbol{\square} \text { Site } & \boldsymbol{\square} \text { Design } \\
\mathbf{\square} \text { Construction Processes } & \boldsymbol{\square} \text { Construction Materials } \\
\mathbf{\square} \text { O\&M } & \boldsymbol{\square} \text { End-of-Life }
\end{array}
$$

Fig. 1. A perspective on cradle-to-grave (i.e., five stages) impacts of building processes as percentages of $\mathbf{C} \mathbf{I}_{\text {lifespan }}$ for a commercial building.

Figure 1 shows a perspective of the relative impacts that the interactive processes of design and management are expected to have on percentages of $\mathbf{C} \mathbf{I}_{\text {lifespan }}$ for a typical commercial building during the various stages of a building's lifespan. As shown, the anticipated impacts differ substantially from those in the RICS Information Report [1], and which were also reported as $70-80 \%$ from operations, $15 \%$ for embodied carbon [5-6] during manufacture of products for buildings (i.e., from cradleto-gate), and only minor influences from site selection, design decision-making, construction, and demolition.

The rationale for these differences in percentages is fundamental. From the authors' experiences in designing buildings and evaluating building performance, the values shown in Fig. 1 are based on the perspective that designing and managing for cradle-to-grave carbon emissions involves interactive decision-making during all stages of a building's lifespan (i.e., cradle-to-grave). As indicated in Fig. 1, decisions made during the stages of siting, design, construction, and demolition may have more influence on carbon emissions from a building over its lifespan (e.g., 65\%) than operational activities (e.g., $35 \%$ ). Conversely, the RICS process limits the estimates of embodied carbon emissions (e.g., 15\%) to only surveys or audits of the cradle-to-gate processes, without iteration.

\subsection{Concept of Embodied and Operational Carbon}

In this concept, which has some similarities to the concept proposed by Moncaster and Symons [5], two routes of carbon emissions are defined together with expressions of limits of error, or uncertainties.

\subsubsection{Embodied Carbon}

This term characterizes the amount of carbon emitted into the atmosphere (i.e., greenhouse gases - GHG), soil, or water during the production of materials, products and assemblies that are used in the siting, construction, operations, and demolition of a building. Typically, this term is expressed as the " $\mathrm{CO}_{2}$ equivalent" $\left(\mathrm{CO}_{2} \mathrm{e}\right)$. Embodied carbon is usually expressed in the literature as kilograms of $\mathrm{CO}_{2} \mathrm{e}$ per unit mass (e.g., $\mathrm{kg}$ ) or surface area (e.g., $\left.\mathrm{m}^{2}\right)$ of the product or material.

Carbon emissions are associated with energy consumption (embodied energy) and chemical processes during the extraction, manufacture, transportation, assembly, construction, replacement and deconstruction of materials or products.

Embodied carbon for a site-specific building can be calculated but not explicitly measured from cradle-togate, cradle-to-site, cradle-to-end of construction, cradleto-grave, or even cradle-to-cradle. Typically, embodied carbon datasets, which have been calculated, are found in the literature as cradle-to-gate $[1,5-6]$.

\subsubsection{Operational Carbon}

This term characterizes the amount of carbon emitted from combustion processes and the use of chemicals during the operational stage of a building's lifespan. Typically, this term is expressed as the $\mathrm{CO}_{2} \mathrm{e}$ and 
includes both gaseous and particulate components from combustion processes.

Operational carbon emissions, which can be explicitly measured in site-specific buildings, include those from on-site sources (e.g., furnaces, boilers, fireplaces) and off-site sources (e.g., district heating and cooling plants, and electrical power stations). These emissions are from combustion processes to control the so-called regulated loads in the building (e.g., heating, cooling, ventilation, lighting, and permanently connected electrical appliances) and unregulated/plug loads (e.g., IT components, cooking, refrigeration, and entertainment appliances that are not permanently connected to electrical outlets) [2-3]. Operational carbon also includes carbon emissions from energy and chemicals for maintenance, repair, housekeeping, and renovation processes.

\subsubsection{Limits-of-Error and Uncertainties}

As a credible design tool, the variances of calculated CIs must be sufficiently narrow, in terms of standard errors or confidence intervals, for designers to discern significant differences among alternative materials and systems with regard to embedded and operational emission rates. To determine the uncertainties in $\mathbf{C I}$ lifespan calculations, propagation-of-error analyses are also included as part of this concept.

Limits-of-error are defined in terms of six types of measurement errors (i.e., systemic, random, resolution, operator bias, environmental factors, and computational), and two types of interpretation errors (i.e., false positive and false negative) [10]. Uncertainty should be calculated as the propagation of measurement and interpretation errors within the system being analyzed, in terms of $\mathbf{C I}_{\text {lifespan }}$ and Eq. (3).

Without control of the limits-of-error, the uncertainties of measurement in initial simulations are likely to be relatively large at the conceptual design phase (e.g., $+/-20-50 \%$ or larger for EUIs) [9-11]. Although not typically used by designers, an uncertainty analysis provides credibility in the results that can be used by fiduciary decision-makers.

\section{Calculation Procedures}

\subsection{Overview for Design Decisions}

The purpose of these CI calculations is to enable a designer to select among alternative materials, components and systems with which to optimize the amount of carbon emissions while providing for the health and well-being of the occupants (i.e., objective functions) and achieving the functional performance of the facility (i.e., constraints). In this paper, the objective functions of the CI calculations are considered only in terms of $\mathrm{CO}_{2} \mathrm{e}$ emissions into the atmosphere.

\subsubsection{Objective Functions}

In this concept, the cradle-to-grave Carbon Index (CIlifespan) for a design alternative is the objective function, expressed as the sum of the Carbon Indices for each of the five stages ( $\sum$ CIstage).

The Carbon Index for each stage is expressed as the sum of the Carbon Indices for the elements that comprise that stage $\left(\sum \mathbf{C I} \mathbf{I}_{\text {element }}\right)$. And the Carbon Index for each element is the scalar multiplication of two factors: PF and CIF [7]:

$$
\mathrm{CI}_{\text {element }}=\mathbf{C O}_{2 \text { element }}=P F \cdot \mathbf{C I F}
$$

\subsubsection{Primary Factor (PF)}

The $P F$, a scalar value, is defined and quantified by the designer in terms of the primary dimension (e.g., $\mathrm{kg}, \mathrm{km}$, etc.) of each element being considered in the alternative designs (e.g., materials, assemblies, and systems).

\subsubsection{Carbon Impact Factor (CIF)}

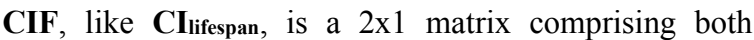
embodied and operational components, defined as follows.

- The embodied $\mathrm{CO}_{2} \mathrm{e}$ in the element that is to be installed in the building; and

- The operational $\mathrm{CO}_{2} \mathrm{e}$ that is emitted from an element during the operations of the building.

As defined, here, CIF is a technical factor that converts $P F$ to embodied and operational values of $\mathrm{CO}_{2} \mathrm{e}$. However, CIFs may also include non-technical (e.g., policy) values such as the social cost of carbon, which can destablize the use of CIFs and can vary by country and time [12].

CIFs may be defined by the designer in terms of sitespecific "relative" values for comparison between alternatives, or as "standardized" values that are determined regionally, nationally, or internationally for comparisons with baseline values $[1,5-6]$.

\subsubsection{Constraints}

Cradle-to-grave CIs ( $\left.\mathbf{C I}_{\text {lifespan}}\right)$ are intended to apply for buildings that will be occupied. So, to protect occupant health, safety, and well-being, CIFs are likely to have additional constraints (such as quality of insulation for thermal and moisture resistance, and paints and coatings for fire-resistance) that comply with codes, standards, and other criteria, rather than cradle-to-gate CIs that are typically available in literature [1, 5-6].

Affordability, enforceability, and measurability are other constraints that are likely to limit the values of the CIFs, which may reduce the potentials to minimize the site-specific values of the CIFs [10]. 


\subsection{Site Specific Procedures}

Unlike other concepts $[1,5-6]$, the $\mathbf{C I}_{\text {lifespan }}$ concept introduced here is comprised of five stages of a building's lifespan. Each of these stages requires the determination of $\mathbf{C I} \mathbf{I}_{\text {stage }}$ and $\mathbf{C I} \mathbf{I}_{\text {element }}$ within the stages. Each element is defined in terms of $P F$ and CIF in Equation (2):

- Primary Factors (PF) (e.g., distances to resources of materials to be transported $(\mathrm{km})$; area of wall assembly $\left(\mathrm{m}^{2}\right)$; capacity of chiller $(\mathrm{kW})$ ); and

- Carbon Impact Factors (CIF) (e.g., $\mathrm{kg} \mathrm{CO}_{2} \mathrm{e} /$ $\mathrm{L}$ fuel) $x$ ( $\mathrm{L}$ fuel $/ \mathrm{km}) ; \mathrm{kg} \mathrm{CO}_{2} \mathrm{e} / \mathrm{m}^{2} ; \mathrm{kg}$ $\mathrm{CO}_{2} \mathrm{e} / \mathrm{kW}$ ) that characterize the embodied and operational carbon in the PFs[1, 5-7]

The sum of the products of the PF and CIF values across the relevant elements will yield Carbon Indices for the five stages (CI $\left.\mathbf{I}_{\text {stage }}\right)$. While determining the quantitative values for the $P F \mathrm{~s}$ is difficult enough, obtaining valid and reliable values for the CIFs is even more difficult, which are just now becoming available $[1,5-6]$.

The sum of the carbon indices over the lifespan is defined in this paper as the Carbon Index (CI lifespan $_{\text {): }}$

$$
\begin{gathered}
\mathrm{CI}_{\text {lifespan }}=\sum \mathrm{CO}_{2} \text {, site }+\sum \mathrm{CO}_{2} \text {, design } \\
+\sum \mathrm{CO}_{2} \text {, const }+\sum \mathrm{CO}_{2}, \text { o\&M }+\sum \mathrm{CO}_{2} \text {, end-of-life }
\end{gathered}
$$

\subsubsection{Site Selection ( $\Sigma \mathrm{CO}_{2}$, site)}

Although architects and engineers may not be initially involved in selecting the geographic or demographic location of the site, it is important that they provide advice to the owner about the impact on the CI due to the building's location on the site, $\Sigma \boldsymbol{C O}_{2}$,site, including:

- Building placement and orientation on the site;

- Proximity to resources from the site (e.g., fuel, electrical power, water and sewer);

- Routes and distances for transportation of materials and people to and from the site.

The Carbon Index for the site selection may be expressed as:

$$
\begin{gathered}
\mathrm{CI} \text { site }= \\
\sum \mathrm{CO}_{2} \text {, orientation }+\sum_{2} \mathrm{CO}_{2}, \text { resources }+
\end{gathered}
$$

\subsubsection{Orientation}

The placement and orientation of a proposed building on the selected site can affect the other CIs shown in Equation 3 :

- "Massing" and material selections for the building enclosure/envelope;

- Thermal, daylighting, and acoustic loads to be controlled;

- Capacities and control strategies for the HVAC and other systems;
- Embodied carbon in the selected building components, equipment, and systems; and

- Rates of energy and water utilization during the building's operations.

To calculate $\Sigma \boldsymbol{C O}_{2}$, orientation, the following interrelated information will be required for each alternative placement and orientation of the building [5], with sufficient accuracy to make design decisions (see Section 2.2.2):

- Mass of each façade based on expected structural, thermal, daylighting, and acoustic loads (i.e., PFs); and the corresponding embodied carbon CIFs from cradle-to-grave) (e.g., $\mathrm{kg} \mathrm{CO}_{2} \mathrm{e} / \mathrm{kg}$ or $\mathrm{m}^{3}$ material) from standardized reference sources. [1, 5-6].

- $\quad$ Estimated sizes and material property characteristics of perimeter and interior components and systems to provide for the health, safety, security, and functional requirements of the facility $(P F \mathrm{~s})$; and the corresponding embodied CIFs from cradle-tograve, such as $\mathrm{kg} \mathrm{CO}_{2} \mathrm{e} / \mathrm{kg}$ material, from standardized reference sources.

- Projected annual energy and water utilization rates and savings $(P F \mathrm{~s})$ over the lifespan of the building structure (e.g., 30 years); and the corresponding operational carbon impact factors (CIFs from cradle-to-grave, such as $\mathrm{CO}_{2 \mathrm{e}} / \mathrm{kWh}$, and $\mathrm{CO}_{2 \mathrm{e}} /$ liter $\mathrm{H}_{2 \mathrm{O}}$ ) from standardized reference sources

\subsubsection{Proximity to Resources}

The placement and orientation of a proposed building on the selected site will also affect the amount of embodied carbon in:

- Lengths of wiring, cabling and conduits, and locations of transformers between the connections to the building and the locations of the electrical substations;

- Lengths of piping or other means of transmission for natural gas or other fossil fuels from substations; and

- Lengths of piping and locations of pumps from sources of potable and other water supplies, sanitary and storm water sewers, and other sites of discharge or recycling.

To calculate $\Sigma \mathrm{CO}_{2}$, resources, the following information will be required:

- The distances from the utility entrances into the building to the nearest available electrical, fuel, and water resources and disposal sites;

- The material property characteristics; and the corresponding embodied CIFs from standardized reference sources or site-specific calculations. 


\subsubsection{Transportation of Materials and People to and from the Site}

The site selection will also affect access for construction, and for operations over the expected life-span of the building.

To calculate $\sum \mathrm{CO}_{2}$, transportation, the following information will be required:

- Estimated distances to the site from employees' residences by private and public transportation over the lifespan of the building (e.g., 30 years); and the corresponding embodied CIFs from standardized reference sources.

- Estimated distances from sources of materials to the site for functional use in the building over the life-span of the building (e.g., 30 years); and the corresponding CIFs for transporting the materials, from standardized reference sources.

\subsubsection{Design $\left(\Sigma \mathrm{CO}_{2}\right.$, design $)$}

The design process includes conceptual design, detailed design, and development of construction documentation. This interactive process is likely to have a significantly larger influence on the amount of cradle-to-grave carbon emissions from a building over its lifespan than anticipated in the non-iterative survey approach described in the RICS Information Paper [1] or in the Moncaster and Symons paper [5]. A common evidential outcome is that errors of omission and commission are reduced during this design process. Neither [1] or [5] consider the impact of design on cradle-to-grave $\mathrm{CO}_{2} \mathrm{e}$.

Currently, standards of practice are not yet available with which "designers of record" can be fully prepared to implement the Carbon Index calculations at the design phase, which is basically an expansion of building energy analyses. Although methods of calculation and measuring are both advancing [9], calculations of site energy utilization (e.g., $\mathrm{kWh} / \mathrm{m}^{2}$ ) vary from metered values by $20-50 \%$. Introduction of the Carbon Index will increase the complexity of these calculations, including the need to define limits-of-error and uncertainty analyses [10].

During the design process, architects and engineers must design the architectural and other building systems such as HVAC, daylighting, electrical lighting and power, and plumbing systems for the health, safety, security of the occupants, and the functional requirements of the facility. These requirements impose certain limitations on the design and on material and equipment selections. Therefore, in selection of the materials and equipment, architects and engineers must depend on valid and reliable CIFs, and limits-of-error information, for all the selected products [5-6]. These CIFs must be standardized in both the specifications and on drawings.

The Carbon Index for the design processes may be expressed as:

$\sum \mathrm{CO}_{2}$, design $=\sum \mathrm{CO}_{2}$, arch $+\sum \mathrm{CO}_{2}$, struct

$+\sum \mathrm{CO}_{2}$, civil $+\sum \mathrm{CO}_{2}$, mech $+\sum \mathrm{CO}_{2}$, elec

\subsubsection{Architectural}

As the design for a new or renovation project progresses through the conceptual, detail, and documentation phases, types and quantities of materials, finishes, and furnishings are identified, detailed, and specified.

To calculate $\Sigma \boldsymbol{C O}_{2}$, arch, the following information will be required:

- Specification of quantity and quality of materials, components, and assemblies that comply with expected structural, thermal, lighting, chemical and acoustic loads.

- Optimization and/or selection of corresponding CIFs from standardized reference sources, including chemical emission and decay rates, durability, resiliency, and energy efficiency.

The architect should stipulate, in the specifications and on the drawings, the $\mathbf{C} \mathbf{I}_{\text {lifespan }}$ requirements that have to be met during construction and operations (i.e., occupancy).

\subsubsection{Structural}

As the design progresses through the conceptual, detail, and documentation phases, types and quantities of materials are identified, detailed, and specified, such as concrete and masonry, steel and other metals, wood, and composite materials that support static and dynamic loads on the building.

To calculate $\sum \boldsymbol{C O}_{2}$,struct, the following information will be required:

- $\quad$ Specification and scheduling of the quantity and quality of structural systems that comply with expected static (e. g., weight) and dynamic (e.g., rain, wind, seismic) loads on the building.

- Optimization and/or selection of corresponding CIFs from standardized reference sources.

\subsubsection{Civil}

As the design progresses, types and quantities of materials are identified, detailed, and specified, such as concrete, metals, wood, and composite materials that support the development and maintenance of on-site streets, sidewalks, landscaping, water supply networks, sewers, and solid waste management.

To calculate $\sum \boldsymbol{C O}_{2}$, civil, the following information will be required:

- Specification and scheduling of the quantity and quality of civil systems that comply with expected use of the site.

- Optimization and/or selection of corresponding CIFs from standardized reference sources. 


\subsubsection{Mechanical}

As the design progresses, types and quantities of HVAC, plumbing, fire and smoke control, and other mechanical systems are identified, detailed, and specified.

To calculate $\sum \mathrm{CO}_{2}$, mech, the following information will be required:

- Specification and scheduling of the quantity and quality of mechanical systems that comply with expected structural, thermal, and acoustic loads.

- Optimization and/or selection of corresponding CIFs, such as energy efficiency, resiliency, longevity, reliability, maintainability from standardized reference sources.

\subsubsection{Electrical}

As the design progresses, types and quantities of lighting, power, security, information technology (IT), and other electrical and electronic systems are identified, detailed, and specified.

To calculate $\sum \mathrm{CO}_{2}$, elec, the following information will be required:

- $\quad$ Specification and scheduling of the quantity and quality of electrical and electronic systems that comply with expected electrical, structural, chemical, and thermal loads.

- Optimization and/or selection of corresponding CIFs, such as energy efficiency, outgassing, resiliency, longevity, reliability, maintainability from standardized reference sources.

\subsubsection{Construction $\left(\Sigma \mathrm{CO}_{2}\right.$, const)}

The construction industry does not yet have standardized information available with which to assume the responsibility and accountability for implementing the Carbon Index values, which will be specified in drawings and specifications, through the processes of bidding, constructing, commissioning, and delivering the project. Examples of issues to be addressed include:

- During pre-construction, shop drawing must be in compliance with architect/engineer's Carbon Index requirements stipulated in the project specifications and drawings. When conflicts arise, who determines compliance (e.g., the $\mathrm{A} / \mathrm{E}$ ) and on what basis? For example, the contractor finds materials or equipment with the values of embodied carbon at locations exceeding a specified distance of the source (e.g., > $800 \mathrm{~km}$ (500 mi) radius, [e.g., from [1]) but with lower first costs.

- During construction, materials (e.g., construction forms and installed elements), power equipment such as robots, and transportation of materials and workforce must be in compliance with the specified CIFs and resultant carbon indices.
- During project delivery and acceptance by the owner. If Functional Commissioning or Acceptance Testing is within the scope of the project [9], a demonstration of compliance with the specified CIFs and carbon indices must also be in compliance for the functional systems.

- If modifications are needed during commissioning or acceptance testing, that require changes in material or equipment, this step is required to demonstrate changes in embodied and/or operational $\mathrm{CO}_{2} \mathrm{e}$ emissions.

The Carbon Index for the three phases of construction includes: 1) transportation of construction materials, equipment, and workforce to the construction site; 2) well-being and productivity of the workforce; and 3 ) effectiveness of construction methods.

The Carbon Index for the construction processes may be expressed as:

$$
\begin{array}{r}
\sum \mathrm{CO}_{2}, \text { const }=\sum \mathrm{CO}_{2}, \text { transportation } \\
+\sum \mathrm{CO}_{2}, \text { workforce }+\sum \mathrm{CO}_{2}, \text { const methods }
\end{array}
$$

\subsubsection{Transportation}

Manufacturers and suppliers should be prepared to provide their products from within a maximum radius (e.g.800 km [1]) from the construction site for each system, such as HVAC, envelope, plumbing, and electrical. When not feasible, alternatives should be included in the specifications and drawings, so that offsetting CIFs can be provided.

\subsubsection{Workforce}

An educated and skilled workforce can reduce waste and increase productivity on the construction site $[8,10]$. These characteristics can be represented by embodied CIFs for the site. How these factors can be standardized should be defined by the workforce and construction industry.

\subsubsection{Construction Methods}

New techniques in structural, mechanical, electrical, and plumbing construction are leading to more modular construction and potential for lower CIFs. How these factors can be standardized should be defined by the workforce and construction industry.

\subsubsection{Operations and Maintenance $\left(\Sigma \mathrm{CO}_{2}, \mathrm{O \& M}\right)$}

Once the building is accepted by the owner and all systems are in operation, the performance of the building is expected to sustain an environment that provides for the health, safety, security, and well-being of the occupants while meeting the owner's functional requirements. However, the functional and environmental requirements of the initial or subsequent owners are likely to change over the expected lifespan of the building's structure (e.g., 30 years or more). These 
subsequent changes are also likely to change the needs for: 1) energy and water resources; 2) maintenance, repairs and renovations; and 3) housekeeping procedures.

As carbon emissions are associated with each of these $\mathrm{O} \& \mathrm{M}$ functions, variations in the rates of emissions (i.e., embodied and operational carbon) will occur that will require a life-cycle approach to determining a Carbon Index for the entire operational period.

The Carbon Index for the operations and maintenance processes may be expressed as:

\section{$\sum \mathrm{CO}_{2}, \mathrm{O \& M}=\sum \mathrm{CO}_{2}$, energy and water $+\sum \mathrm{CO}_{2}$, maintenance and repair$$
+\sum \mathrm{CO}_{2} \text {, housekeeping }
$$

Owners and facilities managers are not fully prepared to accept the responsibility and accountability for sustaining a life-cycle Carbon Index through operations and maintenance, as methods for determining them and assuring their accuracies are not yet available $[5-6,8,10]$.

\subsubsection{Energy and Water Resources}

HVAC, lighting, electrical power, and plumbing systems, which operate to satisfy occupant needs in commercial and institutional buildings currently account for approximately $18 \%$ of the annual energy use [13], and approximately $17 \%$ of the annual withdrawals for buildings from public water supplies in the U.S [14]. These processes also emit substantial amounts of carbon (e.g., as $\mathrm{CO}_{2} \mathrm{e}$ ) over the life-cycle of the building.

Calculating the values of operational Carbon Index, $\sum \mathrm{CO}_{2}$, energy and water, at the building site or at the source is expected to be at least as controversial as calculating source- vs. site-energy indices, which have been debated by the various producers and suppliers for decades.

Moreover, methods of generating power at central plants with different fossil fuels, nuclear reactors, hydropower or solarpower will result in substantially different CIFs if calculated at the building site or at the source of power generation, especially if site-generated power is exported to the electric grid.

The availability of on-site sources of power or potable water, including microgrids, ground-source heat/power systems, solar thermal and photovoltaic systems, wind turbines, and spring or deep-well water, adds another question about whether CIFs for energy and water at the source or site of delivery should be used in calculating carbon indices, as these on-site sources function as "demand-response" applications at the site. For example, if on-site power or potable water is generated in excess of on-site demand, and the excess is exported to the electric or supply water grid rather than stored on-site, how should the $\Sigma \mathrm{CO}_{2}$, energy and water be determined?

For thermodynamic consistency, it is rational that the operational Carbon Index for energy and water utilization should be calculated at the boundary of the building's footprint with appropriate CIFs for the on-site source equipment and materials.

\subsubsection{Maintenance, Repair and Renovation}

From the time of initial occupancy, the building, its systems, and its components will begin to degrade unless operational care is continuously provided. The first level of care is routine or preventive maintenance; the second level is repair, and the third level is replacement or renovation. Each of these processes involves the use of energy, water, and chemicals.

To calculate $\sum \mathrm{CO}_{2}$, maintenance and repair at each of the three levels, the following information will be required:

- $\quad$ Specification and scheduling of the quantity and quality of maintenance, repair, and renovation procedures that comply with expected functional requirements of the facility.

- Optimization and/or selection of corresponding CIFs from standardized reference sources.

\subsubsection{Housekeeping and Environmental Services}

In commercial and institutional facilities, the meaning of the term "housekeeping" is now often considered to also mean "Environmental Services," which includes cleaning and sanitizes public areas and private spaces to facility or hospital standards [16]. Environmental Services also includes other housekeeping duties, such as doing the laundry, assuring cleaning supplies are well stocked and available, and performing garbage pickup and disposal. Housekeeping and Environmental Services involves the use of energy, water, and chemicals.

To calculate $\sum \mathrm{CO}_{2}$, housekeeping, the following information will be required:

- Specification and scheduling of the quantity and quality of housekeeping and environmental services that comply with expected functional requirements of the facility.

- Optimization and/or selection of corresponding embodied and operational CIFs from standardized reference sources.

\subsubsection{End-of-Life and Recycling ( $\Sigma \mathrm{CO}_{2}$, end-of-life)}

When a facility, or a portion thereof, is deemed to no longer safely or economically provide its function, it will likely be renovated, rebuilt, or demolished. A typical time for this occurrence is about 30 years after its initial construction [1]. This so-called "end-of-life" stage will involve three processes: 1) de-construction; 2) waste disposal; and 3) salvaging, reclamation and recycling.

The Carbon Index for the end-of-life processes may be expressed as:

$$
\begin{aligned}
& \sum \mathrm{CO}_{2}, \text { end-of-life }=\sum \mathrm{CO}_{2}, \text { deconstruction } \\
& +\sum \mathrm{CO}_{2} \text {, disposal }-\sum \mathrm{CO}_{2}, \text { recycling }
\end{aligned}
$$


Owners, facilities managers, designers of record, and contractors, are not fully prepared to accept the responsibility and accountability for achieving an "endof-life" Carbon Index, as methods for determining its values and assuring its accuracies are not yet available $[5-6,8]$.

\subsubsection{Deconstruction}

Depending on the complexities of the site and building, the process of deconstruction may involve planning, design, demolition and, potentially, reconstruction.

To calculate $\sum \mathrm{CO}_{2}$, deconstruction, the following information will be required:

- Specification of quantity and quality materials, components, assemblies, and systems that must be removed for disposal, reuse, or recycling.

- Optimization and/or selection of corresponding operational CIFs for the removal processes, from standardized reference sources.

\subsubsection{Waste Disposal}

In the deconstruction process, decisions must be made regarding which materials are to be disposed as waste, and which materials are to be salvaged for reuse or recycling.

To calculate $\Sigma \mathrm{CO}_{2}$, disposal, the following information will be required:

- Identification and separation of the materials, components, assemblies, and systems that are to be transported to waste disposal sites from those that are to be salvaged.

- Optimization and/or selection of corresponding PFs and operational CIFs for salvaging, from standardized reference sources.

\subsubsection{Reclamation and Recycling}

Materials, components, assemblies and systems, which are to be salvaged, will retain some of their characteristics, including embodied carbon. If the items are to be reused or recycled, use of additional energy and chemicals will likely be required, which will result in additional embodied carbon. If the Carbon Index for reclamation/reuse/recycling, $\sum \boldsymbol{C O}_{2}$, recycling is smaller than the Carbon Index for waste disposal, $\sum \boldsymbol{C O}_{2}$, disposal, then the effect will be a net reduction in the Carbon Index for the "end-of-life" process.

To calculate $\sum \mathrm{CO}_{2}$, recycling, the following information will be required:

- Determination of the embodied Carbon Indices from the existing $P F \mathrm{~s}$ and CIFs for the items to be reused or recycled, from standardized reference sources;

- Calculations for the additional embodied Carbon Indices from the new $P F \mathrm{~s}$ and CIFs needed to reuse or recycle the items, also from standardized reference sources.
- Determination of the net differences in Carbon Indices between the processes for reuse/recycle and waste disposal.

\section{Benchmarks}

Public and private policy-makers typically set "benchmarks" to establish performance goals. The concept of benchmarking Carbon Indices for buildings may be considered analogous to benchmarking energy utilization, such as the US EPA's "Energy Star" program (i.e., ES $>75$ to qualify the building for Energy Star Certification) [16]. That program required several years of obtaining sufficient data from buildings to establish credibility. Yet, even today, much controversy persists regarding the accuracy of the ES benchmark [e.g., 11]. It is anticipated that the development of a credible CI benchmark will require even more effort than for energy use benchmarks, due to the larger number of variables to be considered [e.g., 6].

Three Carbon Indices will result from the processes described above: 1) $C I_{\text {lifspan [embodied], the embodied }}$ carbon in the materials and equipment that were designed and installed in the building; 2) $C I_{\text {lifespan [operational], the operational carbon emitted }}$ during the lifespan of the building; and 3) $C_{l_{\text {lifespan,em+op }} \text {, }}$ the sum of embodied and operational components. All three Carbon Indices should be displayed and compared to the appropriate benchmarks:

- Within the completed construction documents, the designer of record should indicate the sitespecific benchmark and corresponding Carbon Index that is to be achieved at the time of completion of the construction.

- As part of the project delivery process, the sitespecific benchmark and corresponding lifespan Carbon Index should be posted on the building to indicate the expected amounts of carbon emitted from energy and material utilization by the facility and its employees, and for traveling to and from their residences. As reported in some British articles, various forms of carbon indices are now being posted on some buildings.

\section{Conclusions and Recommendations}

The development of a Carbon Index as a "cradle-tograve tool" for interactively designing and managing building performance is a logical extension of current engineering practice : from an energy analysis of a sitespecific building in terms of its normalized Energy Utilization Index $\left(\mathrm{kWh} / \mathrm{m}^{2}\right.$ floor area), to an analysis of its global-warming potential (GWP) in terms of the normalized cradle-to-grave Carbon Index $\left(\mathrm{kg} \mathrm{CO} \mathrm{CO}_{2} \mathrm{e} / \mathrm{m}^{2}\right.$ floor area)

However, because of the increased number of variables that must be considered, the procedures to determine valid and reliable values for site-specific, Cradle-to-Grave Carbon Indices ( $\left.\mathbf{C I}_{\text {lifespan }}\right)$, will be more 
complex and most likely will require the use of advanced computer programs.

With the advancement in highly sophisticated computer technology, it is feasible to extend privately and publically accessible software programs to include processes for calculating a $\mathbf{C} \mathbf{I}_{\text {lifespan }}$ for the design of a commercial or institutional building, including its systems and equipment. Issues to be resolved include:

- Validation of the calculated results with measured data from site-specific buildings.

- With current building technology, the time required to create computer models of sitespecific alternatives with multiple CIFs will become significantly more complex than current practice demands.

- Advances in computer technology, and data acquisition and analytics, suggest that needed changes in design procedures will become practical within a relatively short period of time.

- Both technical and non-technical CIFs are expected to have shorter lifespans than the whole building lifespan, which will affect the stability of the $\mathbf{C I}_{\text {lifespan }}$

- It is anticipated that the development of credible benchmarks for the $\mathbf{C I}_{\text {lifespan will require }}$ standardization of two major procedures: 1) identifying and quantifying critical sets of Primary Factors $(P F \mathrm{~s})$ that characterize carbon emissions at each of the five stages in the building's life; and 2) establishing "Carbon Impact Factors" (CIFs) that accurately characterize the impact of the design or operational element on agreed upon target outcomes, such as "global warming potential" (GWP) and "sustainability."

While achieving standardization of the procedures for $P F \mathrm{~s}$ may be difficult, it is feasible as it would be based on methods that are now used in planning, design, and construction practice, particularly those used for energy calculations. But standardizing on credible CIFs will be substantially more difficult:

- First, the target outcomes must be defined in measurable terms and within expected limits-oferror.

- Second, agreements on values must be obtained before benchmarks can be established.

- Third, the basic barriers will be developing processes to ensure valid and reliable values with which designers will be accountable. Until then, risk to the designer will increase.

If the industry and the Authorities having Jurisdiction (AHJ) pursue vigorously, perhaps it is possible to implement "cradle-to-grave" carbon indices $\left(\mathbf{C I}_{\text {lifespan }}\right)$ for site-specific buildings. Introducing a valid and reliable cradle-to-grave Carbon Index as a design tool enables transition of policies to reduce global warming and to enhance sustainability with which planners, architects, engineers, contractors, owners and managers can credibly evaluate the total amount of embodied and operational carbon emitted through the five stages of a building's lifespan.

The authors thank Christopher McGahey, Ph.D. at Setty and Associates, Ltd. for his insight and assistance in the research and preparation needed for this article.

\section{References}

1. . Embodied Carbon Working Group of the Royal Institution of Chartered Surveyors. Methodology to calculate embodied carbon of materials. Coventry CV4 SJE, UK : Royal Institution of Chartered Surveyors (RICS), (2012).

2. ANSI/ASHRAE/IES Standard 90.1-2016: Energy Standard for Buildings Except Low-Rise Residential Buildings. Atlanta, (2016).

3. ANSI/ASHRAE/IES/USGBC Standard 189.12016: Standard for the Design of High-Perfirmance Green Buildings Except Low-Rise Residential Buildings. Atlanta, USA, (2016).

4. B.S. Setty, J.E. Woods. Toward Fully Functional Net-Zero-Energy Buildings: An Engineerinng Perspective. Fairfax, Virginia, Setty and Associates, (2014).

5. A.M. Moncaster, K.E. Symons. A method and tool for "cradle to grave" embodied carbon and energy impacts of UK buildings in compliance with new TC 350. Energy and Buildings 66, 514 (2013).

6. P. Wu, Y. Feng, J. Pienaar, B. Xia. A review of benchmarking in carbon labelling schemes for building. Journal of Cleaner Production. http://dx.doi.org/10.1016/j.jclepro.2015.07.067, (2015).

7. J.E. Woods, cost avoidance and productivity in owning and operating buildings. In: Occupational Medicine: State of the Art Reviews, 4, 753 Philadelphia, Hanley \& Belfus. Inc., October (1989).

8. J.E. Woods. The future of an educated and skilled workforce (ESW) in buildings: challenges and opportunities. ICB/TABB Journal, 1, 18, (2014).

9. B.S. Setty, Total building commissioning: a case study of the U.S. District Courthouse, Salt Lake City, Utah, U.S.A. Proceedings of Society of Environmental Engineers, Clima 2013, - 11th REHVA World Congress, paper 458, (2013).

10. J.E. Woods, The future of an educated and skilled workforce: availability and use of appropriate instrumentation. ICB/TABB Journal, 2, 19, (2015).

11. J.H. Scofield, Energy star building benchmarking scores: good idea, bad science, Proceedings of ACEEE Summer Study on Energy Efficiency in Buildings, p 3-267, (2014). 
12. K. Ricke, L. Drouet, K. Caldeira, M. Tavoni. Country-level social cost of carbon, Nature Climate Change 8, 895-900, (2018):

https://www.nature.com/articles/s41558-018-0282-y ; accessed 24oct18,

13. U. S. DOE. Use of Energy in the U.S. https://www.eia.gov/energyexplained/index.php?pag e=us energy use; accessed 14mar19.

14. U.S. EPA. Facility Types. https://www.epa.gov/watersense/types-facilities; accessed 14mar19.

15. K, Meier. Definition of Environmental Service Hospital Job; http://work.chron.com/definitionenvironmental-service-hospital-job-28675.html; accessed 14mar19.

16. U.S. EPA. Benchmarking Energy Use (Energy Star): https://www.energystar.gov/buildings/aboutus/how-can-we-help-you/benchmark-energyuse/benchmarking; accessed 14mar19.

\section{Glossary of Terms}

From RICS [1] with editorial modifications:

Carbon Emissions: Shorthand terms for the emissions of any of the number of greenhouse gases (GHG) that affect climate change. Carbon emissions are usually expressed as $\mathrm{CO}_{2} \mathrm{e}$ (i.e. $\mathrm{CO}_{2}$ equivalent), which is a calculated value based on the relative impact of a given gas on global warming (the so called global warming potential GWP). For example, if methane has a global warming potential of 25 , it means that $1 \mathrm{~kg}$ of methane has the same impact on climate change as $25 \mathrm{~kg}$ of carbon dioxide and thus $1 \mathrm{~kg}$ of methane would count as $25 \mathrm{~kg}$ of CO, equivalent.

Cradle-to-Gate: Carbon emissions between the confines of the 'cradle' (earth) up to the factory gate of the final processing operation. This includes mining, raw materials extraction, processing and manufacturing.

Cradle-to-Grave: Carbon emissions between the confines of the 'cradle' (earth) to gate (factory gate of the final processing operation), to site (delivery to the site of use), to-end of construction, plus maintenance, refurbishments, demolition, waste treatment and disposals ('grave').

Cradle-to-Site: Cradle-to-gate emissions plus delivery to the site of use (construction/installation site).

Embodied Carbon: Carbon emissions associated with energy consumption (embodied energy) and chemical processes during the extraction, manufacture, transportation, assembly, replacement and deconstruction of construction materials or products. Embodied carbon can be calculated from cradle-togate, cradle-to-site, cradle-to-end of construction, cradle-tograve, or even cradle-to-cradle. The typical embodied carbon datasets are cradle-to-gate. Embodied carbon is usually expressed in kilograms of $\mathrm{CO}_{2}$,e per kilogram of product or material.

Operational Carbon: Carbon emissions associated with energy consumption (operational energy) while the building is occupied. This includes the so-called regulated load (e.g., heating, cooling, ventilation, lighting) and unregulated/plug load (e.g., IT equipment, cooking and refrigeration appliances). It also includes carbon emissions from embodied energy and chemicals for maintenance, repair, housekeeping, and renovation processes.

Recycled Content: The portion of a product that contains materials that have been recovered or otherwise diverted from the solid waste stream.

From this paper:

Carbon Index: A calculated 2x1 matrix comprising embodied carbon and operational carbon components, which together represent, in units of $\mathrm{CO}_{2}$ equivalent, the total amount greenhouse gases (GHG) emitted during the five stages of a building's lifespan. 